\title{
Prevalence of Molar Incisor Hypomineralisation Among School Children aged 7-12 years in Tunis, Tunisia
}

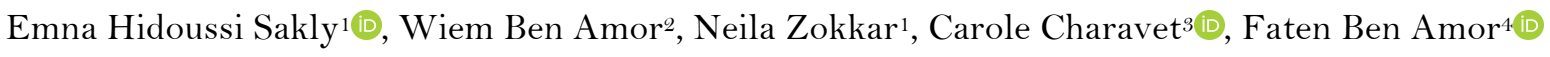

\begin{abstract}
${ }^{1}$ Department of Restorative Dentistry-Endodontics, Oral Health and Orofacial Rehabilitation Laboratory Research (LR12ES1 1), Faculty of Dental Medicine of Monastir, University of Monastir, Monastir, Tunisia.

2Department of Orthodontics and Dentofacial Orthopaedics, Oral Health and Orofacial Rehabilitation Laboratory Research (LR12ES11), Faculty of Dental Medicine of Monastir, University of Monastir, Monastir, Tunisia.

${ }^{3}$ Department of Orthodontics and Dentofacial Orthopaedics, University Hospital of Liège, Liège, Belgium.

${ }^{4}$ Department of Anatomy, Oral Health and Orofacial Rehabilitation Laboratory Research (LR12ES11), Faculty of Dental Medicine of Monastir, University of Monastir, Monastir, Tunisia.
\end{abstract}

Author to whom correspondence should be addressed: Dr. Emna Hidoussi Sakly, Department of Restorative DentistryEndodontics, Faculty of Dental Medicine, Vicenne Avenue, 5000 Monastir, Tunisia. E-mail: minoumd@gmail.com

Academic Editor: Alessandro Leite Cavalcanti

Received: 17 May 2020 / Review: 23 July 2020 / Accepted: 05 August 2020

How to cite this article: Sakly EH, Amor WB, Zokkar N, Charavet C, Amor FB. Prevalence of Molar Incisor Hypomineralisation among school children aged 7-12 years in Tunis, Tunisia. Pesqui Bras Odontopediatria Clín Integr. 2020; 20:e0094. https://doi.org/10.1590/pboci.2020.160

\begin{abstract}
Objective: To evaluate the prevalence and the characteristics of Molar Incisor Hypomineralisation (MIH) in 7-12-year-old children in Tunis, Tunisia. Material and Methods: This study was designed as a crosssectional study, in which school children aged 7 to 12 years were included. A total of 510 children (257 girls and 253 boys) who had their first permanent molar and incisors were evaluated using the 2003 European Academy of Paediatric Dentistry (EAPD) recommendation criteria were examined. Descriptive data analysis and Pearson's chi-squared test were performed $(\mathrm{p}<0.05)$. Results: A total of 510 children were included in the study. MIH was present in $35.4 \%$ of our study population. Boys exhibited slightly higher MIH (19,4\%) and Post Eruptive Breakdown (PEB) (7,3\%) prevalence compared to girls, but the difference was not statistically significant $(\mathrm{p}=0.07)$. Moreover, demarcated opacities were more prevalent than PEB. More precisely, the main prevalence without PEB was MIH with white/creamy demarcated opacities, which was more frequent than yellow/brown demarcated opacities $(\mathrm{p}<0.05)$. Conclusion: The prevalence of MIH in Tunis was $35.4 \%$, with no difference between girls and boys. The main MIH type prevalence was white/creamy demarcated opacities without PEB.
\end{abstract}

Keywords: Tooth Abnormalities; Dental Enamel Hypoplasia; Molar; Paediatric Dentistry. 


\section{Introduction}

Different diagnostic terms such as 'cheese molars', 'non-fluoride enamel opacities', 'idiopathic enamel opacities', and 'opaque spots' have been used to define developmental enamel defects, according to a clinical characterization of enamel or their etiological factors [1,2].

In 2003, the term Molar Incisor Hypomineralisation (MIH) was introduced by Weerheijm et al. to describe white or yellow-brown demarcated opacities on first permanent molars, frequently associated with affected permanent incisors [3]. In fact, enamel abnormalities are among the most common structural abnormalities in dental tissue. Specifically, MIH is a particular form of developmental enamel defect affecting the first permanent molars, associated or not to permanent incisors, and is the consequence of a disorder that occurs during pregnancy, at birth and in the first months of life. This causes damage to the enamel of developing teeth during this period [4].

Several factors have been implicated in the aetiology of MIH. In the literature, MIH has been linked to environmental changes, and a variety of systematically acting medical factors have been described such as prenatal, perinatal and postnatal problems as well as respiratory diseases, high fever diseases (e.g., chickenpox), low birth weight or frequent use of antibiotics during early childhood [4,5]. It has also been proposed that an underlying genetic predisposition contributes to the risk of developing MIH [6]. The relevance of each event is difficult to establish as many of these events can occur more than once during early childhood [7].

Clinically, the MIH lesion's severity may vary from white to yellow/ brownish demarcated opacities to structural loss under masticatory forces [8]. This Post Eruptive Breakdown (PEB) exposes the dentin, which can be extremely sensitive, making children unable to effectively carry out their oral hygiene and make their teeth more vulnerable to rapidly progressing caries [9]. This may result in atypical cavities or even complete coronal distortion, requiring extensive restorative treatment [10,11].

Therefore, patients and parents often report complaints due to $\mathrm{MIH}$, including pain or sensitivity mainly during toothbrushing or breathing cold air, aesthetic problems notably for incisor teeth, rapid dental wear and loss of enamel, inclination to caries and eventually tooth loss. From a dental point of view, the problems are related to the unexpectedly rapid development of caries in the erupting first permanent molar, the inability to anaesthetize the MIH molar when treatment is indicated, and the unpredictable behaviour of apparently intact opacities [8]. Severely affected posterior teeth need prompt restoration as a result of enamel disintegration and subsequent caries, while anterior teeth frequently present demanding aesthetic management [11]. Finally, it has been reported that children with MIH require 10 times more dental treatment than unaffected children, and MIH is considered the most urgent problem in paediatric dentistry [12,13].

Therefore, the prevalence of MIH has been thoroughly investigated worldwide, and it varies from $2.9 \%$ in China [14] to 40.2\% in Brazil [15]. In Tunisia, while MIH constitutes a serious public health problem, no previous epidemiological study assessing the prevalence of this pathology has been carried out, and knowledge about MIH and its management is very limited due to this lack of research. Thus, carrying out a survey focusing specifically on the prevalence of $\mathrm{MIH}$ in Tunisia contributes to expanding the overall worldwide literature on this subject, providing relevant data to clinicians, including general dentists, pedodontists, orthodontists and also paediatricians, promoting further research and, setting up adequate treatment protocols. Therefore, this study aimed to determine, for the first time, the prevalence and characteristics of MIH in 7-12-year- old children in Tunis, Tunisia.

\section{Material and Methods}




\section{Study Design}

This is a cross-sectional study conducted in Tunis, Tunisia. The district of Tunis is not an endemic fluorosis area.

\section{Participants, Eligibility, and Setting}

This study was conducted in a sample of 510 school children (7 to 12 years old, 257 girls and 253 boys) in one randomly chosen school from Tunis, Tunisia in December 2017. The inclusion criteria were as follows: age between 7 and 12 years and having at least one of the permanent first molars and or incisors fully or partially erupted (minimum 1/3rd of clinical crown height). The exclusion criteria were as follows: generalised developmental defects such as amelogenesis imperfecta or fluorosis and systemic disease history.

\section{Dental Examinations}

Prior to the beginning of the study, a calibration exercise was carried out for the examiner with the help of the paediatric dentist. A set of 20 photographs, including both $\mathrm{MIH}$ and other enamel developmental defects, was used to calibrate the examiners. The Kappa test was used to analyze intra and inter-examiner agreements with values of 0.7 and 0.82 , respectively.

All children were invited to sit on a chair during the examination. Dental examinations were performed in the reserved classroom by four examiners using a mouth mirror with a headlight. The teeth were brushed before dental examinations to remove plaque or food waste.

\section{Data Collection}

The permanent first molars and the upper and lower incisors were studied in each patient. The surfaces examined were as follows: 1) Permanent first molars: buccal, occlusal and lingual/palatal surfaces and 2) Upper and Lower incisors: labial surface. The 2003 European Academy of Paediatric Dentistry (EAPD) recommendation criteria were employed for scoring the MIH [11], according to a code form from 0 to 10 (Table 1). During the analysis, it was assumed that unerupted teeth did not have MIH; thus, code 6 was also considered as code 0 [16]. Also, both the white/creamy demarcated opacities with PEB and yellow/brown demarcated opacities with PEB were included in a group of teeth with PEB.

Table 1. Criteria for scoring MIH according to European Academy of Paediatric Dentistry.

\begin{tabular}{cl}
\hline Code & \\
\hline 0 & Cnamel defect free \\
1 & White/creamy demarcated opacities, no PEB \\
1 a & White/creamy demarcated opacities, with PEB \\
2 & Yellow/brown demarcated opacities, no PEB \\
2 a & Yellow/brown demarcated opacities, with PEB \\
3 & Atypical restoration \\
4 & Missing because of MIH \\
5 & Partially erupted (i.e. less than 1/3 of the crown height) with evidence of MIH \\
6 & Unerupted or partially erupted with no evidence of MIH \\
7 & Diffuse opacities (not MIH) \\
8 & Hypoplasia (not MIH) \\
9 & Combined lesion (diffuse opacities/ hypoplasia with MIH) \\
10 & Demarcated opacities in incisors only \\
\hline
\end{tabular}


Statistical Analysis

The collected data were analyzed using the IBM SPSS version 20.0 for Windows (IBM Corp., Armonk, NY, USA). A descriptive analysis of the prevalence and distribution of the clinical recordings was performed. Pearson's chi-squared test was applied. A p-value $<0.05$ was considered as statistically significant.

Ethical Aspects

The study received approval from the Ethics Committee of Dental Medicine University (No: 2017/06). After being fully informed of the purpose and benefits, the children's parents/guardians were invited to sign an informed consent form. Authorization to conduct the study was obtained from school authorities.

\section{Results}

Overall, the prevalence of MIH was found to be $35.4 \%$, equal to 181 children. Molar involvement, with or without involvement of the incisors, was slightly more prevalent in boys compared to girls, but this difference was statistically non-significant $(\mathrm{p}>0.05)$. The overall details are provided in Table 2 .

Table 2. Distribution of children affected by MIH according to gender.

\begin{tabular}{lcccc}
\hline \multirow{2}{*}{ Teeth } & \multicolumn{2}{c}{ Gender } & Total & \\
& Boys & Girls & & p-value \\
& $\mathrm{N}(\%)$ & $\mathrm{N}(\%)$ & $\mathrm{N}(\%)$ & \\
\hline Molars & $49(9.6)$ & $41(8.0)$ & $90(17.6)$ & 0.397 \\
Molars and Incisors & $50(9.8)$ & $41(8.0)$ & $91(17.8)$ & 0.338 \\
\multicolumn{1}{c}{ MIH Total } & $99(19.4)$ & $82(16.0)$ & $181(35.4)$ & 0.370 \\
\hline
\end{tabular}

Table 3 describes the involvement of incisor with the increase in number of affected molars. The white/creamy demarcated opacities (score 1) were more prevalent than yellow/ brown demarcated opacities (score 2 ), as presented in Table 4 .

Table 3. Distribution of children according to pattern of affected first molars and incisors.

\begin{tabular}{ccccccccccccc}
\hline $\begin{array}{c}\text { Number of Molars } \\
\text { Involved }\end{array}$ & \multicolumn{1}{c}{ Number of Incisors Involved } & \multicolumn{4}{c}{ Total } \\
\hline 0 & 329 & 1 & 2 & 3 & 4 & 5 & 6 & 7 & 8 & 330 \\
1 & 10 & 5 & 0 & 0 & 0 & 0 & 0 & 0 & 0 & 15 \\
2 & 22 & 12 & 14 & 4 & 4 & 2 & 0 & 0 & 0 & 58 \\
3 & 8 & 1 & 6 & 2 & 4 & 2 & 0 & 0 & 0 & 23 \\
4 & 32 & 18 & 28 & 0 & 4 & 2 & 0 & 0 & 0 & 84 \\
Total & 401 & 36 & 49 & 6 & 12 & 6 & 0 & 0 & 0 & 510 \\
\hline
\end{tabular}

Table 4. Distribution of score of MIH according to number of molars and incisors.

\begin{tabular}{|c|c|c|c|c|}
\hline \multirow[t]{2}{*}{ Score MIH } & \multicolumn{2}{|c|}{ Molars } & \multicolumn{2}{|c|}{ Incisors } \\
\hline & $\mathrm{N}$ & $\%$ & $\mathrm{~N}$ & $\%$ \\
\hline $\mathrm{O}$ & 1812 & 88.6 & 3970 & 97.3 \\
\hline 1 & 162 & 7.92 & 96 & 2.36 \\
\hline 2 & 4 & 0.2 & 2 & 0.05 \\
\hline 3 & 43 & 2.11 & 11 & 0.27 \\
\hline 4 & 11 & 0.55 & 1 & 0.02 \\
\hline 5 & 7 & 0.35 & $\mathrm{O}$ & 0.0 \\
\hline 6 & 1 & 0.05 & o & 0.0 \\
\hline Total & 2040 & 100.0 & 4080 & 100.0 \\
\hline
\end{tabular}


Finally, PEB was slightly more present in boys compared to girls, but this difference was not significant (Table 5).

Table 5. Distribution of Post Eruptive Breakdown (PEB) by gender.

\begin{tabular}{ccccc}
\hline \multirow{2}{*}{ PEB } & Boys & Girls & Total & p-value \\
& $\mathrm{N}(\%)$ & $\mathrm{N}(\%)$ & $\mathrm{N}(\%)$ & \\
\hline No PEB & $220(43.1)$ & $219(42.9)$ & $439(86.1)$ & 0.07 \\
PEB & $37(7.3)$ & $34(6.7)$ & $71(13.9)$ & \\
Total & $257(50.4)$ & $253(49.6)$ & $510(100.0)$ & \\
\hline
\end{tabular}

\section{Discussion}

Among the myriad of structural anomalies that the practitioner may encounter, MIH appears to be the most frequent and can cause severe tissue damage in the absence of early diagnosis and management. This amelogenesis anomaly seems to be a widespread pathology in industrialized countries with a prevalence increasing gradually over the past 30 years [8].

The aim of this study was to evaluate the prevalence of MIH in children of 7-12-year-olds in Tunis using the 2003 European Academy of Paediatric Dentistry (EAPD) recommendation criteria [3]. The 7 to 12year age group was primarily selected for the reason that by this age, at least one of the first molars has erupted in all children. Furthermore, this choice avoids masking the effect of advanced carious lesions and extractions, which can minimize the chance of proper diagnosis [9]. Moreover, various researchers have used different criteria for recording the presence of MIH, such as the Developmental Defects of Enamel index (DDE index) or the modified DDE index, but the EAPD criteria remains the most widely used and relevant criteria $[13,17]$.

The present study showed an MIH prevalence of 35.4\% amongst schoolchildren in the Tunis district. Previous worldwide studies have shown a prevalence of MIH from 2.4\% in China [14] to 40.2\% in Brazil [15]. This wide range of prevalence rates in other studies could be related to the different indices and criteria, examination variability, recording methods, and different age groups [18,19]. Overall, Tunisia has a rather high level of prevalence of MIH. Therefore, MIH is a major public health issue to be considered in Tunisian children's dental health. Interestingly, Danish children with a prevalence of MIH of $37.3 \%$ have the closest prevalence rate to our study [20].

In a previous study [7], the authors observed varying $\mathrm{MIH}$ prevalence by geographic location because Brazil is a country with significant socioeconomic discrepancies, which results in an uneven distribution of oral diseases in its population. Residents of the rural areas are at greater risk for the development and aggravation of oral diseases. This may be due to either the greater concentration of public health services in the urban areas or the more limited access of the rural population to the public health interventions [7].

Nevertheless, due to our inability to predict if an unerupted tooth is defective or not, in our study, all unerupted teeth were considered to have no defect, which might account for an underestimation of the prevalence of MIH in our chosen population.

More precisely, this study revealed that MIH was not significantly correlated with gender, in agreement with other studies [7,13]. Some studies have hypnotized that gender may be a contributing factor to the development of MIH. They have noticed a higher prevalence of MIH among males. Our study did not confirm this gender predisposition for MIH. 
Moreover, in the same patient, the prevalence of only molars affected (17.6\%) compared to incisors and molars both affected was identical $(17.8 \%)$. The literature appears to be in accordance with our results. In the study of Mittal and Sharma, which involved 1,240 schoolchildren in India, it was demonstrated that the prevalence of affected molars compared to affected incisors were almost equal [19]. Additionally, it was reported that $31 \%$ and $35.8 \%$ of all Danish children had affected molars and incisors, respectively. Furthermore, no correlation between the involvement of the molars and the incisors was found [20].

Other studies in varied populations Nepal [16] and India [14,17], have demonstrated a relationship between the number of affected molars and number of incisors involved. This may be explained by the severity of the etiological factors, which could simultaneously affect the molars and incisors. The finding of several affected teeth of the same tooth type may support the hypothesis of the systemic origin of demarcated opacities, which will most likely affect all teeth developing during the period where the systemic factor is effective [20].

The clinical presentation of the MIH defect is variable, from demarcated yellow or creamy white opacities to brownish defects, with or without loss of enamel. In our study, the most commonly observed lesion was creamy white opacity, which is the least severe lesion [8]. The results obtained by Mittal and Sharma [19] corroborate our findings, showing a higher percentage of white/creamy opacity lesions.

This result accounts for the factors involved in the MIH pathology. As stated previously, the MIH causing factors act for a short period during amelogenesis, thus reducing the MIH defect [21-24]. Consequently, preventive intervention, such as remineralization therapy at an early stage, can minimize the proportion of PEB.

Finally, teeth with PEB were more prevalent in boys compared to girls, whereas in our study, the difference was not significant. It was also demonstrated that boys have a higher risk of PEB than girls, but the difference was not significant [21]. However, Wogelius et al. found that PEBs were more prevalent in girls than in boys (7.4\% vs. 4.2\%) [20]. This difference could be related to the eruption age of teeth in girls, which appears at the age of nine and therefore preceding boys by several months [21].

The main limitation of the present study was the non-evaluation of total number of faces of teeth and the frequencies of schoolchildren of each age. However, this limitation may not have affected the overall findings of our study. Studies of larger samples and other populations will be necessary to confirm our results.

\section{Conclusion}

The prevalence of MIH was $35.4 \%$ in the district of Tunis. No difference between boys and girls was found for either MIH prevalence or for PEB. The most commonly observed lesion was creamy white opacity. Further studies to map the prevalence in different geographical areas are required for public health authorities to formulate MIH's preventive policies.

\section{Authors' Contributions}

EHS
$\begin{array}{lll}\text { WBA } 0000-0001-5958-4651 & \begin{array}{l}\text { Conceptualization, Methodology, Formal Analysis, Resources, Writing - Original } \\ \text { Draft Preparation and Writing - Review and Editing. } \\ \text { Resources. }\end{array} \\ \text { NZ } & \text { (D) } & \text { Resources and Supervision. } \\ \text { CC } & \text { (D) } 0000-0003-1624-4205 & \text { Writing - Review and Editing. } \\ \text { FBA } & \text { (D) } 0000-0002-4620-9921 & \text { Supervision. }\end{array}$
All authors declare that they contributed to critical review of intellectual content and approval of the final version to be
published.




\section{Financial Support}

None.

\section{Conflict of Interest}

The authors declare no conflicts of interest.

\section{Acknowledgements}

The authors wish to acknowledge the immense help and support they received from Professor Moncef Rassas while conducting this study.

\section{References}

[1] Weerheijm KL, Groen HJ, Beentjes VE, Poorterman JH. Prevalence of cheese molars in eleven-year-old Dutch children. ASDC J Dent Child 2001; 68(4): 259-62.

[2] Leppaniemi A, Lukinmaa PL, Alaluusua S. Nonfluoride hypomineralizations in the permanent first molars and their impact on the treatment need. Caries Res 2001; 35(1): 36-40. https://doi.org/10.1159/000047428

[3] Weerheijm KL, Duggal M, Mejare I, Papagiannoulis L, Koch G, Martens LC, et al. Judgement criteria for molar incisor hypomineralisation (MIH) in epidemiologic studies: a summary of the European meeting on MIH held in Athens, 2003. Eur J Paediatr Dent 2003; 4(3):110-3.

[4] Crombie F, Manton D, Kilpatrick N. Aetiology of molar-incisor hypomineralization: a critical review. Int J Paediatr Dent 2009; 19:73-83. https://doi.org/10.1111/j.1365-263X.2008.00966.x

[5] Preusser SE, Ferring V, Wleklinski C, Wetzel WE. Prevalence and severity of molar incisor hypomineralization in a region of Germany - a brief communication. J Public Health Dent 2007; 67:148-50. https://doi.org/10.1111/j.17527325.2007.00040.x

[6] Jeremias F, Pierri RA, Souza JF, Frageli CM, Restrepo M, Fioti LS, et al. Family-based genetic association for MolarIncisor Hypomineralization. Caries Res 2016; 50(3):310-8. https://doi.org/10.1159/000445726

[7] Costa-Silva CMD, Jeremias F, DeSouza JF, Cordeiro RCL, Pinto LS, Cristina A. Molar incisor hypomineralization: prevalence, severity and clinical consequences in Brazilian children. Int J Pediatr Dent 2010; 20(6):426-34. https://doi.org/10.1111/j.1365-263X.2010.01097.x

[8] Weerheijm KL. Molar incisor hypomineralization (MIH): clinical presentation, aetiology and management. Dent Update 2004; 31(1):9-12. https://doi.org/10.12968/denu.2004.31.1.9

[9] William V, Messer LB, Burrow MF. Molar incisor hypomineralization: review and recommendations for clinical management. Pediatr Dent 2006; 28(3):224-32.

[10] Lygidakis NA, Chaliasou A, Siounas G. Evaluation of composite restorations in hypomineralised permanent molars: a four-year clinical study. Eur J Paediatr Dent 2003; 3(3):143-8.

[11] Mathu-Muju K, Wright JT. Diagnosis and treatment of molar incisor hypomineralization. Compend Contin Educ Dent 2006; 27(11):604-10.

[12] Giuca MR, Lardani L, Pasini M, Beretta M, Gallusi G, Campanella V. State-of-the-art on MIH. Part. 1 Definition and aepidemiology. Eur J Paediatr Dent 2020; 21(1):80-2. https://doi.org/10.23804/ejpd.2020.21.01.16

[13] Jälevik B. Prevalence and diagnosis of molar-incisor-hypomineralisation (MIH): a systematic review. Eur Arch Paediatr Dent 2010; 11(2):59-64. https://doi.org/10.1007/BF03262714

[14] Cho SY, Ki Y, Chu V. Molar incisor hypomineralization in Hong Kong Chinese children. Int J Paediatr Dent 2008; 18(5):348-52. https://doi.org/10.1111/j.1365-263X.2008.00927.x

[15] Soviero V, Haubek D, Trindade C, Da Matta T, Poulsen S. Prevalence and distribution of demarcated opacities and their sequelae in permanent 1st molars and incisors in 7 to 13-year-old Brazilian children. Acta Odontol Scand 2009; 67(3):170-5. https://doi.org/10.1080/00016350902758607

[16] Shrestha R, Updhaya S, Bajrachraya M. Prevalence of Molar Incisor Hypomineralization among school children in Kavre. Kathmandu Univ Med J 2014; 12(1):38-42. https://doi.org/10.3126/kumj.v12i1.13631

[17] Shubha AB, Sapna H. Molar-incisor hypomineralization: prevalence, severity and clinical characteristics in 8 to $13-$ year-old children of Udaipur, India. I Indian Soc Pedod Prev Dent 2014; 32(4):322-9. https://doi.org/10.4103/09704388.140960

[18] McDonald RE, Avery DR, Stookey GK. Acquired and Developmental Disturbances of the Teeth. 6th ed. St. Louis: Mosby; 2004. p.122-127. https://doi.org/10.1016/B978-0-323-05724-0.50011-4

[19] Mittal N, Sharma B. Molar incisor hypomineralization: prevalence and defect characteristics in Indian schoolchildren. J Cranio-Maxillary Dis 2015; 4(1):49-56. https://doi.org/10.4103/2278-9588.151904 
[20] Wogelius P, Haubek D, Poulsen S. Prevalence and distribution of demarcated opacities in permanent 1st molars and incisors in 6 to 8-year-old Danish children. Acta Odontol Scand 2008; 66(1):58-64. https://doi.org/10.1080/00016350801926941

[21] Păsăreanu M, Nedelcovici A. Enamel developmental defects and dental caries frequencies in 8-1 1year old children. J Prev Med 2002; 10(4):43-8.

[22] Whatling R, Fearne JM. Molar incisor hypomineralization: a study of aetiological factors in a group of UK children. Int J Paediatr Dent 2008; 18(3):155-62. https://doi.org/10.1111/j.1365-263X.2007.00901.x

[23] Megan D, Andrew DW, Matina VA, Cesar G, Cristopher O, Lori B. Prevalence of molar-incisor hypomineralization in Milwaukee, Wisconsin, USA: a pilot study. Clin Cosmot Investig Dent 2019; 11:109-17. https://doi.org/10.2147/CCIDE.S172736

[24] Kuscu OO, Caglar E, Aslan S, Durmusoglu E, Karademir A, Sandalli N. The prevalence of molar incisorhypomineralization (MIH) in a group of children in a highlypolluted urban region and a windfarm-green energy island. Int J Paediatr Dent 2009; 19(3):176-85. https://doi.org/10.1111/j.1365-263X.2008.00945.x 